\title{
Sub-Periosteal Shunt Valve Insertion to Overcome Shunt Exposure Risks in Predisposed Pediatric Age Group
}

\author{
MOHAMED ELMALLAWANY, M.D.; AYMAN TAREK MAHMOUD, M.D. and HUSSEIN SOFFAR, M.D. \\ The Department of Neurosurgery, Faculty of Medicine, Cairo University
}

\begin{abstract}
Background: Shunting procedure still represents the backbone for the treatment of hydrocephalus. To have an exposed shunt is a nightmare every neurosurgeon wish to avoid encountering in his career. However pediatric patients with hydrocephalus are a predisposed category for this complication, possessing friable and delicate skin, larger head size with added skin stresses on pressure points, occasionally malnourished or premature, all of which can lead to or accelerate the process.
\end{abstract}

Objective: The aim of this study is to address the technique of the pericranial flap and the sub-pericranial shunt valve placement in the pediatric hydrocephalic patients predisposed to shunt exposure due to friable skin in an attempt to overcome this serious complication.

Methods: This study was done prospectively in the Cairo University hospitals, on pediatric patients suffering from hydrocephalus including 40 patients treated between January 2018 and January 2020, having predisposing factors for shunt exposure,operated upon by the technique of elevating a pericranial flap and the sub-pericranial shunt valve placement.

Results: Out of the 40 patient included in the study, none of the cases developed any breakdown of skin or liability for exposure, with viable and healthy skin flaps, all cases had good wound healing, most of the cases requiring shunt insertion do so in the 1 st 6 monhts of age, congenital hydrocephalus $(60 \%)$ was the main etiology for shunt insertion followed by post infection \& post-hemorrhagic etiology, most of the cases (80\%) were below weight for age, 3 cases $(7.5 \%)$ of cases developed shunt malfunctioning requiring revision (2 proximal, 1 distal), 2 cases (5\%) had mild superficial wound infection resolved afterward, none of the cases developed Cerebrospinal Fluid (CSF) leak.

Conclusion: Sub-periosteal shunt reservoir placement is simple, easy, non-time consuming, yet was very effective in reducing the nightmare of shunt exposure \& CSF leak in predisposed malnourished or premature pediatric patient, abolishing the costly and exhausting need for reoperation and shunt transfer or skin grafting and risks of CSF infection.

Correspondence to: Dr. Mohamed Elmallawany, The Department of Neurosurgery, Faculty of Medicine, Cairo University
Key Words: Subperiosteal - Shunt, prematurity - Malnourishement - Ventriculo -peritoneal shunt.

\section{Introduction}

SHUNTING procedure still represents the backbone for the treatment of hydrocephalus [1]

In the United States, approximately 36,000 shunt procedures are performed each year with healthcare related costs for pediatric hydrocephalus approaching \$2 billion dollars annually [2] .

Shunting technique for hydrocephalus is a simple, ubiquitous, typically safe, directly rewarding surgery, yet it can turns into a catastrophic sequlae endangering the outcome of the patient. To have an exposed shunt is a nightmare every neurosurgeon wish to avoid to encounter in his career [3]

However pediatric patients with hydrocephalus are a predisposed category for this complication, possessing friable and delicate skin, larger head size with added skin stresses on pressure points, occasionally malnourished or premature, all of which can lead to or accelerate the process [3].

Other complications like Cerebrospinal Fluid (CSF) leak through the wound, delayed wound healing, wound dehiscence, allergy to hardware components, all can similarly be complicated by shunt exposure with subsequent ventriulitis and meningitis [4].

Friable skin means to have reduced skin thickness either from under development of the skin or its appendages, or decreased subcutaneous tissue, all predispose to skin erosion or necrosis post shunting [4].

In a previous study conducted by Mwang'ombe and Omulo, CSF leak and shunt exposure occurred in nearly $25 \%$ of the included cases which high- 
lights that this complications are frequently encountered in this predisposed category [5]

We hereby try to address the pericranial flap and the sub-pericranial shunt placement in the pediatric hydrocephalic patients in an attempt to overcome the nightmare of having this serious complication.

\section{Patients and Methods}

This study was done prospectively in Cairo University Hospitals, on pediatric patients suffering from hydrocephalus including 40 patients treated between January 2018 and January 2020. Local Ethical Committee approval was obtained. An informed written consent was obtained from all patients. Detailed history and proper examination were performed in all cases. All the patients performed either CT or MRI before deciding the management to assess ventricular size, septations, underlying etiology and to plan best trajectory and length for CSF drainage. Routine preoperative labs were drawn.

\section{Inclusion criteria:}

Pediatric patients with hydrocephalus either congenital (as in Arnold-chiari malformation, aqueductal stenosis, Dandy-walker), post traumatic or post-hemorrhagic hydrocephalus, tumoral hydrocephalus (posterior fossa tumor complicated by hydrocephalus).

Together with having predisposing factors for shunt exposure as prematurity, underweight, malnourishment, large head to body ratio leading to thin friable skin with liability for shunt exposure.

The patients fulfilling the criteria is operated under general anesthesia in supine position, with a head support and shoulder roll, with the head being turned to the contralateral side of shunt insertion.

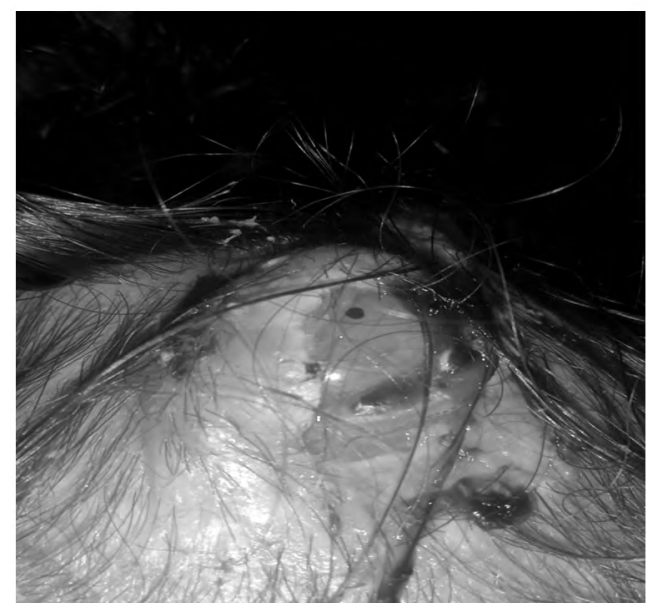

Fig. (1A): A case of exposed shunt.
Either a kocher or keen point is targeted for burr hole insertion of the ventricular catheter on the right side unless there is other indication favouring the left side. Draping is then done.

\section{Skin and periosteal flap:}

A U shaped curvilinear skin incision is done, and either the skin and periosteum is incised as one layer till the bone, or the galea is elevated as a single layer followed by elevation of the periosteum as a separate layer (which is better to have a considerable rim of periosteum at the wound edges for anchoring the valve with silk stitches to it), this is done with the aid of periosteal elevator with creation of a sub-periosteal pocket to accommodate the valve of the shunt.

The skull is drilled, dura is coagulated and incised sharply with blade number 11 . The abdominal incision is incised and the passer with the $T$ shaped handle is tunneled with great care during advancing to the cranial wound to ensure its passage below not above the created sub-periosteal pouch. A medium pressure burr hole $12 \mathrm{~mm}$ shunt was inserted in all cases.

The ventricular and peritoneal catheter is inserted according to the usual anatomical marks, followed by securing the connection points with non-absorbable silk stitches. The shunt valve is anchored to the remaning periosteum at the edges with great care to ensure the knob to be under the subperiosteal flap. This step is important to ensure non migration of the valve within the flap adding stresses and endangering the connection points which can occur with repeated testing of the reservoir throughout the years of follow-up.

The shunt is tested to be functioning well with good distal flow, then the pericranial flap is resutured over then shunt valve to the periosteum at the edges using fine silk 3-0 or 4-0 Fig. (1B).

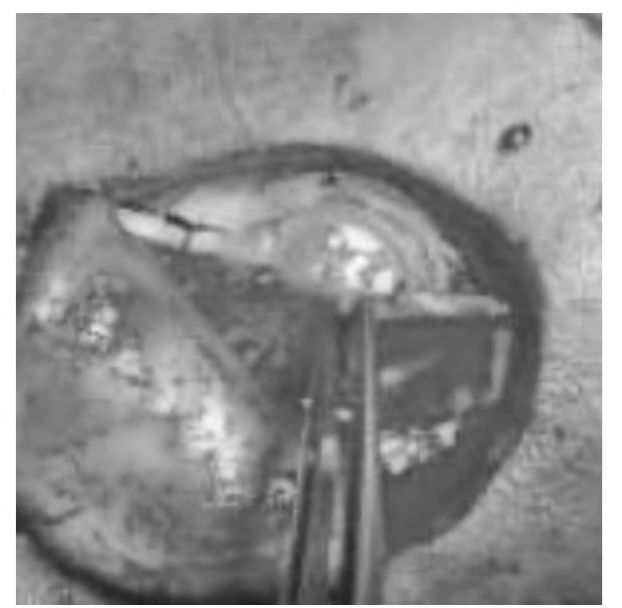

Fig. (1B): Sub-periosteal shunt reservoir insertion. 
The subcutaneous tissues is closed with vicryl $4-0$ and the skin is closed in an interrupted fashion usually with moncryl 3-0 or 4-0.

Post-operatively, the parents are instructed to avoid lying on the operative site till stitch removal. A soft head ring to be used especially in cases with considerable increase in the head size pre operatively.

The patients will be followed in the outpatient clinic for a period of a t least 6 months, to assess the wound healing, stitches removal, skin condition, test shunt functioning, follow-up head size and fontanelle (in open head), any signs of obstruction or infection.

\section{Results}

Age:

The age of the patient ranged from 18 days up to 2.8 years with (24 cases) $60 \%$ of cases had shunt inserted between (1-6 months), (7 cases) $17.5 \%$ between $(6-12 \mathrm{~m}),(12$ cases) $12.5 \%$ between (12$18 \mathrm{~m}),(2$ cases) $5 \%$ between $(18-24 \mathrm{~m})$, and ( 2 cases) $5 \%$ older than 24 months.

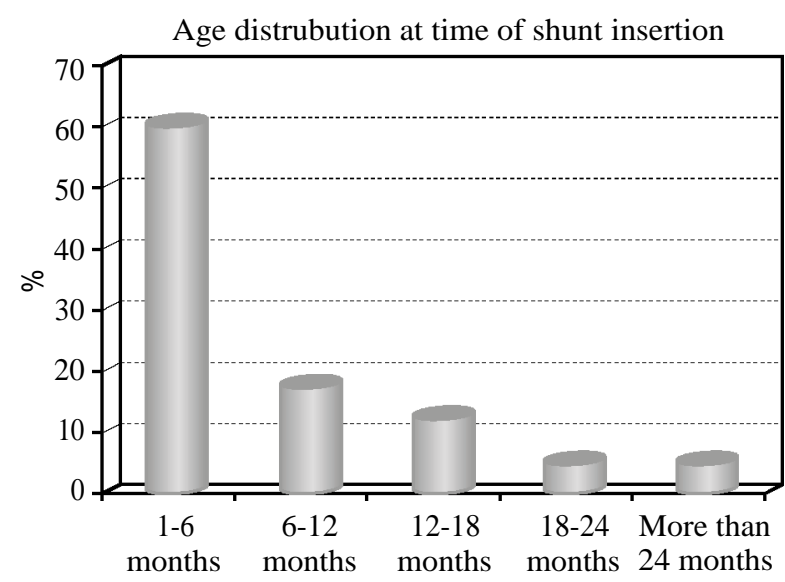

Fig. (2): Age distrubution at time of shunt insertion.

Sex:

Males constitute $57.5 \%$ while female cases $42.5 \%$ with male to female ratio nearly $3: 2$.

\section{Weight:}

Most of the cases [80\%], was below average weight for age (32 cases) while only $20 \%$ ( 8 cases) was within the normal range.

\section{Etiology for shunt insertion:}

Congenital causes constitute the majority of cases $(60 \%)$, Arnold chiari malformation 13 cases $(32.5 \%)$, aqueductal stenosis 9 cases $(22.5 \%)$, dandy walker 2 cases (5\%), while post-hemorrhagic hydrocephalus 6 cases (15\%), post-CSF infection 7 cases $(17.5 \%)$ neoplastic 3 cases $(7.5 \%)$.

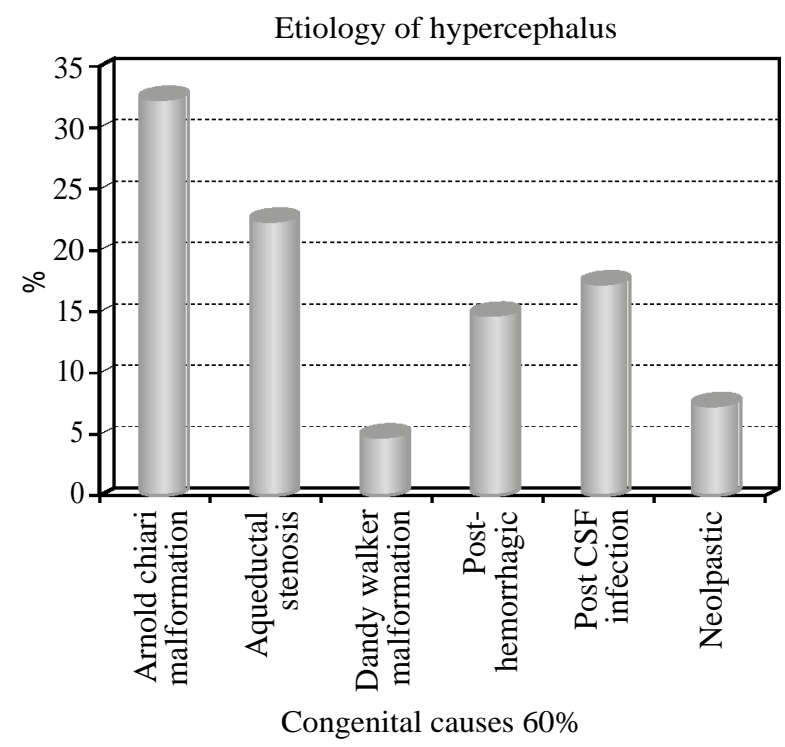

Fig. (3): Various causes of hydrocephalus requiring shunt insertion.

\section{Wound healing:}

Because of malnourishement and the below weigth for age, stitches were removed after 14 days post-operative with no problems encountered regarding gapping or wound dehiscence.

\section{Skin condition:}

The skin flap was viable and healthy in all cases, with no signs of skin breakdown or redness owing to the periosteal layer acting as a barrier between the hardware and the delicate skin.

\section{Shunt pumping:}

We were able to test the shunt reservoir subperiosteally for pumping, during the follow-up period in all cases.

\section{Infection:}

We have 2 cases of mild superficial wound infection which was managed with repeated dressing and local wound care.

\section{Shunt malfunctioning:}

3 cases $(7.5 \%)$ developed shunt malfunctioning requiring revision, 2 proximally (5\%), 1 distally $(2.5 \%)$ during the follow-up period of 6 months.

\section{CSF leak:}

We did not encounter any cases of CSF leak throught the wounds, but only the case of distal obstruction had a mild subcutaneous collection around the shunt track with no leak or collection at the proximal wound site. 


\section{Discussion}

Scalp skin necrosis is uncommon morbidity for shunt placement in adults, but is actually a relatively common complication of Ventriculo-Peritoneal (V-P) shunts in neonates due to inherent skin fragility together with the increased vascular stasis owing to the localized pressure from the reduced head movements during infancy [6]

Many factors was implicated in the pathogenesis of shunt exposure. One of these is localized infection around the shunt material with subsequent abscess with fistula on the skin, leading to exposure. Another factor is the continuous stress on the skin, which on long-term effect will lead to ischemia, ultimately leading to skin necrosis. This mechanism is supported by the fact that the valve and the reservoir of the shunt are the most liable area to exposure [7].

Hamdan A.R. in his retrospective review of shunt complications over 4 years stated that the most common complications were shunt exposure $23 \%$ followed by shunt obstruction $13 \%$ [8] .

In our study, the age at time of shunt insertion was in the ${ }^{1 \mathrm{st}}$ six months in most of cases $(60 \%)$, and 20\% from 6-12 months of age, this is attributed to the fact that congenital causes of hydrocephalus represents the major indication for shunt insertion which should be done as early as possible to control progressive enlargement of head size. While post infectious cases need total resolution of infection with clean CSF and negative cultures before shunt insertion, similarly post hemorrhagic cases need resolution of blood inside the ventricle to decrease incidence of subsequent shunt obstruction.

Similarly, Agarwal $\mathrm{n}$ et al., in their series on pediatric V-P shunt insertion, 71\% (30 out of 41 cases) was due to congenital causes, aqueductal stenosis (18 case), Arnold chiari (10), dandy walker (2) whereas post infectious, post hemorrhagic cases account for $27 \%$ of all cases [9]

In our series, the majority of cases $(80 \%)$ was below weight for age with delicate skin which highlights that malnutrition is a common risk factor for shunt exposure

Similarly, Suryaningtyas et al., in their case series on patients with exposed shunt, found that mal-nourishment was a common contributing factors, and all cases had a poor nutritional condition realted to their body weight which was less than their 50 th or $3 \mathrm{rd}$ percentile to their age group [10]
After the unpleasant encountering of cases with exposed shunts, especially in pediatric patient with thin skin, we started to apply the subperiosteal technique to overcome this nightmare. Early identification and management is essential but the more important is its prevention.

The galea in infants has been shown to have a very little tensile strength, together with delicate subcutaneous tissues [11].

During the traditional hardware placement of the shunt, both the hardware and the reservoir stay at the level of the bone causing pressure and tension on both the site of incision and on the intact skin [12].

Thus, creating a subperiosteal pocket helps to prevent these complications by preventing direct contact of the delicate skin with the synthetic reservoir together with its connections with the proximal and distal end which is also a weak points for disconnection.

Moreover, the periosteum acts as additional reinforcing barrier for the protection of the hardware from external trauma and pressure which is frequent in this patients especially with larger head to body ratio, preterm and malnourished patients.

Furthermore the connection point with the distal end is secured become buried in the depth of the pocket and decreases the incidence of disconnection as a leading cause of shunt malfunction.

The technique of using the thicker layer of periosteum had been described by Mohanty et al., for reducing the incidence of the CSF leak post endoscopic brain procedure by using galeal pericranial flaps [3]

Similary Jain et al., encountered this complication in their study for the insertion of Ommaya reservoir in premature extremely low weight infants having post hemorrhagic hydrocephalus [13].

\section{Tips to improve shunt success rate:}

Hereby are some important tips to reduce the risk of skin breakdown and shunt exposure and increases the success of shunt functioning, which we recommend in this predisposed pediatric age group with delicate skin:

- To reduce the tension on the skin, the U shaped flap should be of acceptable diameter, this will allow proper perfusion of the skin avoiding ischemia and break down.

- Adjusting the size of burr hole to accommodate the shunt reservoir where the lower half should 
be perfectly embedded within the bone and the edge of reservoir to be flush on the same level of bone, will help to reduce the outward bulge of the reservoir decreasing the tension on the skin flap, and help for better test for pumping the reservoir for being functioning well in the follow-up.

- Perfect anchoring of the reservoir edges to the periosteum at the wound edge with nonabsorbable sutures, care must be taken in our technique to leave a rim of periosteum at the wound edge attached to bone, to have a good cuff of the periosteum for fixing the reservoir edge perfectly to it.

- Securing the connections with non-absorbable sutures, between the reservoir to the proximal catheter, and reservoir to distal catheter, being a weak points for disconnection and migration.

-With the addition of the periosteal flap covering the hardware, acting as a barrier between the shunt and delicate skin, reducing the allergic reaction that may occur to the shunt material, acting as a mechanical cushion to external stresses, reducing the possibilities of CSF leak around the shunt tube.

- Delayed removal of stitches to ensure proper wound healing, since many of the pediatric predisposed with mal-nourishment, prematurity, will have delayed wound healing than their peers of same age without this co-morbidities.

\section{Conclusion:}

Sub-periosteal shunt reservoir placement is simple, easy, non-time consuming, yet was very effective in reducing the nightmare of shunt exposure \& CSF leak in predisposed malnourished or premature pediatric patient, abolishing the costly and exhausting need for reoperation and shunt transfer or skin grafting and risks of CSF infection.

\section{References}

1- IGLESIAS S., ROS B., MARTÍN Á., CARRASCO A., SEGURA M., DELGADO A., RIUS F. and ARRÁEZ M.Á.: Surgical outcome of the shunt: 15-year experience in a single institution. Childs. Nerv. Syst., Dec., 32 (12): 2377-85, 2016.
2- SIMON T.D., RIVA-CAMBRIN J., SRIVASTAVA R., BRATTON S.L., DEAN J.M. and KESTLE J.R.: Hydrocephalus Clinical Research Network. Hospital care for children with hydrocephalus in the United States: Utilization, charges, comorbidities, and deaths. J. Neurosurg. Pediatr., 1: 131-7, 2008.

3- MOHANTY A. and SUMAN R.: Role of galeal-pericranial flap in reducing post-operative CSF leak in patients with intracranial endoscopic procedures. Childs Nerv. Syst., 24: 961-4, 2008.

4- BOT G.M., ISMAIL N.J., USMAN B., SHILONG D.J., OBANDE J.O., ALIU S.O., HASSAN I. and SHEHU B.B.: Subpericranial shunt valve placement: A technique in patients with friable skin. Childs. Nerv. Syst., Aug., 30 (8): 1431-3, 2014.

5- MWANG'OMBE N.J. and OMULO T.: Ventriculoperitoneal shunt surgery and shunt infections in children with non-tumour hydrocephalus at the Kenyatta National Hospital, Nairobi. East Afr. Med. J., Jul., 77 (7): 386-90, 2000.

6- KOMOLAFE E.O., ADEOLU A.A. and KOMOLAFE M.A.: Treatment of cerebrospinal fluid shunting complications in a Nigerian neurosurgery programme. Case illustrations and review. In: Pediatr Neurosurg., 44 (1): 36-42, 2008.

7- LEE L., LOW S., LOW D., NG L.P., NOLAN C. and SEOW W.T.: Late pediatric ventriculoperitoneal shunt failures: A Singapore tertiary institution's experience. Neurosurg. Focus., Nov., 41 (5): E7, 2016.

8- HAMDAN A.R.: Ventriculoperitoneal shunt complications: A local study at Qena University Hospital: A retrospective study. Egypt J. Neurosurg., 33: 8, 2018.

9- AGARWAL N., SHUKLA R.M., AGARWAL D., et al.: Pediatric Ventriculoperitoneal Shunts and their Complications: An Analysis. J. Indian Assoc. Pediatr. Surg., 22 (3): 155-7, 2017.

10- SURYANINGTYAS W., RANUH I. and PARENRENGI M.: Shunt exposure as a ventriculoperitoneal shunt complication: A case series International Journal of Surgery Case Reports, Jan., 79: 484-91, 2021.

11- FURNAS D.W.: Temporal osteocutaneous island flaps for complete reconstruction of cleft palate defects. Scand J. Plast. Reconstr. Surg. Hand Surg., 21 (1): 119-28, 1987.

12- CAKIR M.: "Reverse J. Shaped " Skin Flap and Cranial Bone Groove for Shunt Hardware: A New Technique for Patients with Fragile Skin. Turk. Neurosurg., 29 (2): 312$5,2019$.

13- JIAN L., HANG-SONG S., ZHENG-LANG L., LI-SHENG Y., HENG W. and NU Z.: Implantation of Ommaya reservoir in extremely low weight premature infants with posthemorrhagic hydrocephalus: A cautious option. Childs Nerv. Syst., Oct., 28 (10): 1687-91, 2012. 


\section{إدخال الصمام الهحى تحت السمحاق

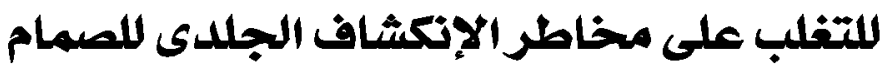

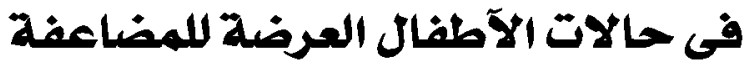

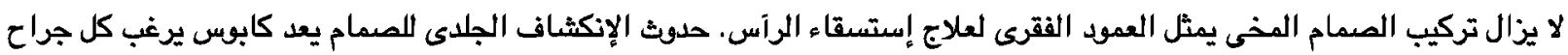

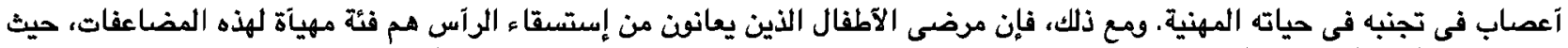

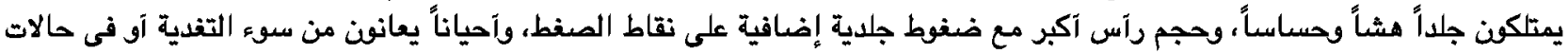

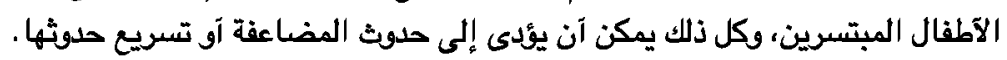

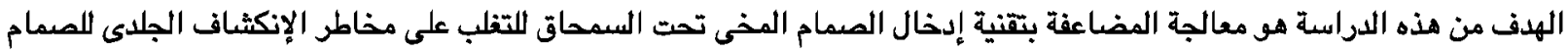

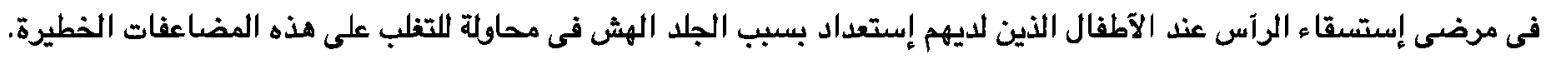

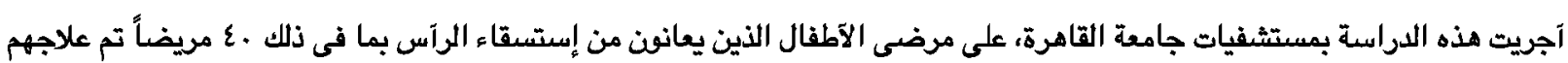

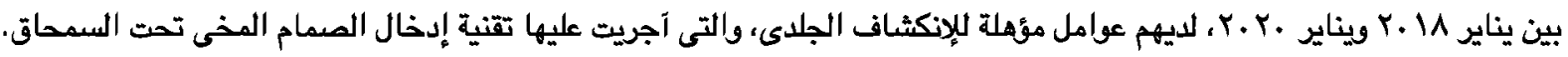

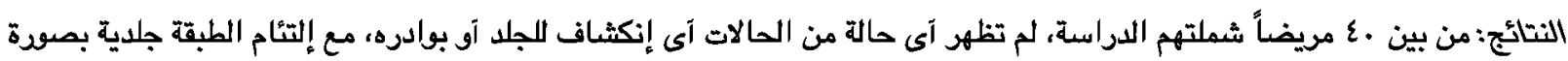

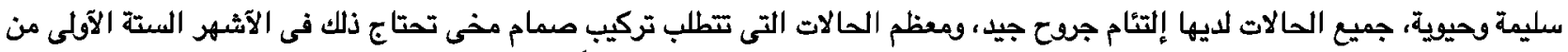

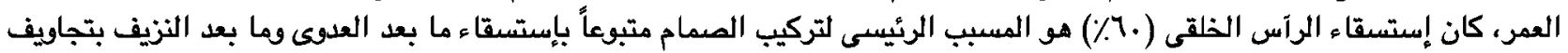

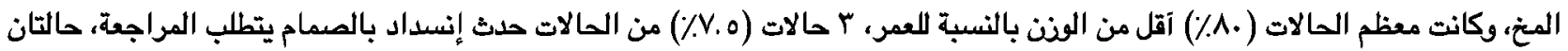

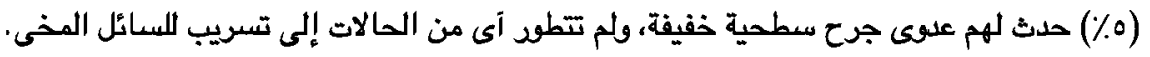

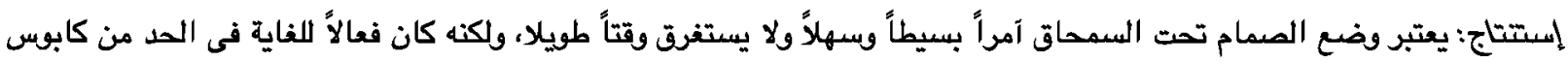

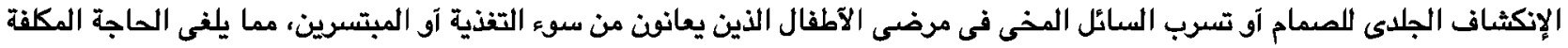
والمرهقة لإعادة الجراحة ونقل الصمام آو ترقيع الجلد. 